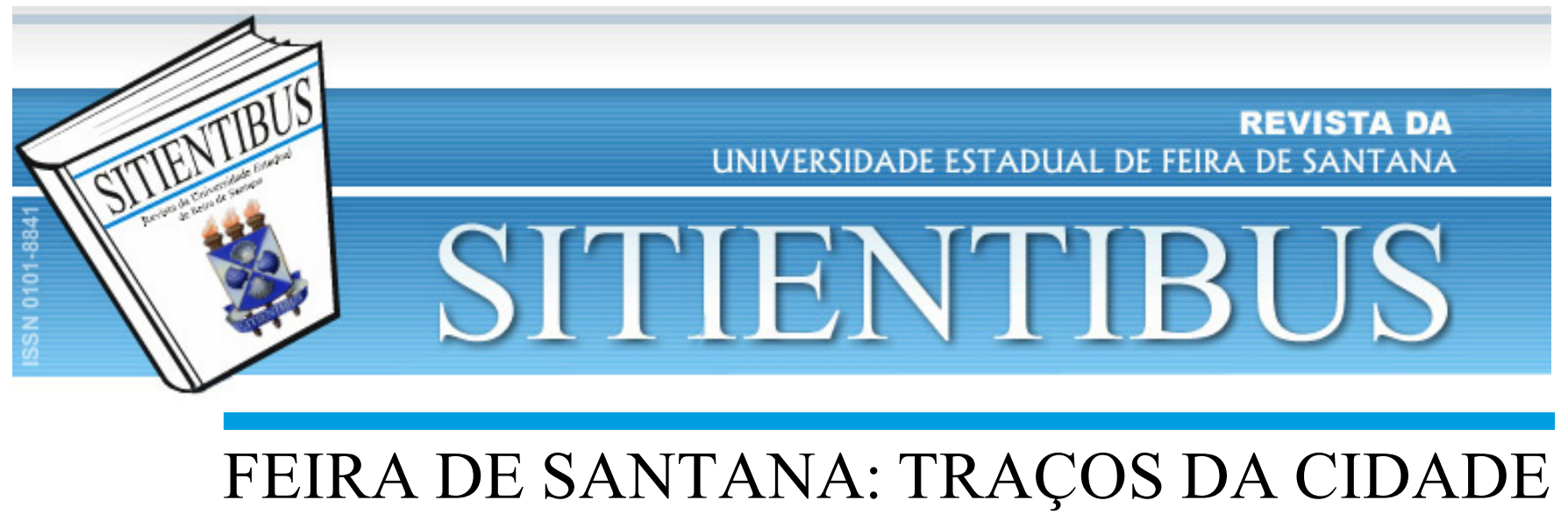

ARTIGO

\title{
A TRAJETÓRIA DO COMÉRCIO E DOS SERVIÇOS DE AUTOPEÇAS EM FEIRA DE SANTANA
}

\section{TRADE AND AUTO PARTS SERVICES TRAJECTORY IN FEIRA DE SANTANA}

ANSELMo PEREIRA de Jesus

Graduado em Geografia/UEFS. E-mail: anselmotor@gmail.com

JANIO SANTOS

Doutor em Geografia/Professor Titular do DCHF-UEFS. E-mail: janiosantos@yahoo.com.br

\section{RESUMO}

Feira de Santana tem em sua gênese a essência comercial, isso em várias vertentes e setores, além de ser um polo dinamizador de toda uma região, que a eleva a uma escala regional, porque atende cerca de 200 municípios com suas atividades comerciais e de prestação de serviços. O foco deste artigo é compreender a história do segmento de autopeças, um setor econômico importante para a organização do centro comercial de Feira de Santana, já que esse segmento possui uma trajetória no centro da cidade.

Palavras-chave: Feira de Santana. Comércio. Autopeças. Espaço urbano.

\section{INTRODUÇÃO}

A cidade é um polo importante de desenvolvimento de uma região, que desde a antiguidade apresenta características peculiares. Uma dessas é prestação de serviços que se concentram na mesma, ainda antes do capitalismo, com característica distinta. Espaço de mutações contínuas, as cidades tendem a ser locus de acumulação de capital. Sendo assim, os espaços onde a área urbana organiza-se moldam-se como produtores de mercadorias diversificadas, em face do avanço das relações capitalistas, especialmente, no processo de globalização, em sua fase atual. As cidades

\section{ABSTRACT}

Feira de Santana has in its genesis the commerce, organized in several sectors. It is also a driving force for the whole region, operates on a macro scale and serves about 200 municipalities with its commercial activities and services. The objective of this article is to understand the history of the auto parts segment, an important economic sector for the organization of the commercial center of Feira de Santana, since this sector has a trajectory for the center of the city.

Keywords: Feira de Santana. Commerce. Autoparts. Urbanspace. 
O presente artigo tem por objetivo central analisar as transformações ocorridas na história do mercado de autopeças em Feira de Santana, sua distribuição e organização espacial na cidade, tendo como base o Centro Comercial. Ou seja, visa mostrar o histórico do comércio autopeças, em face de reestruturação da sua ocupação na cidade de Feira de Santana, tendo como base Centro.

Para analisar esses aspectos, o artigo foi divido em partes distintas: na primeira, trata da relação entre cidade e automóvel; em seguida, a origem do setor, com ênfase no histórico da introdução do automóvel no cenário brasileiro. Por final, alcança a escala de estudo singular, que é a origem do setor de autopeças na cidade de Feira de Santana

\section{A CIDADE, O AUTOMÓVEL E O SETOR DE AUTOPEÇAS}

Segundo Benévolo (1997), a cidade moderna é o palco e o cenário de constantes mutações e embaraços organizacionais, o que é um dos entraves atuais e um desafio constante para as gestões e os envolvidos no planejamento urbano, principalmente voltados para grandes e médios centros e para regiões metropolitanas. Com a ascensão econômica, as facilidades de obtenção crédito e as alterações de consumo que ocorreram na última década no Brasil, o automóvel passou a ser um objeto de consumo mais acessível à população.

Com a modernização, novas tecnologias foram inseridas no mercado de vendas e favoreceram as novas formas de compactação e arrumação dos setores comerciais nas cidades, onde as grandes redes atraem um fluxo de pequenos investidores que tendem a se instalar ao seu redor. Os pequenos investidores que se situam às margens das grandes redes se aproveitam do volume de pessoas que se movimentam por essas áreas para prestarem seus serviços.

Para Santos, a definição dessa atividade leva-nos a refletir que:

O comércio moderno realiza-se através de uma gama de estabelecimentos que vão de grandes lojas, supermercados e mesmo hipermercados, englobando um número considerável de produtos e uma massa importante de consumidores, até as lojas de produtos de moda, que oferecem um pequeno número de artigos de luxo uma clientela selecionada. (SANTOS, 1996, p. 87)

Feira de Santana é uma cidade terciária por essência, como conta sua história. Além de apresentar uma variedade de serviços e produtos que são comercializados nela, é nesse contexto que também se permite falar da origem do mercado de autopeças. $O$ bairro Centro, além de ter limites definidos politicamente, é também aquele que historicamente deu origem a cidade. Por isso, nele se concentram os grandes casarões antigos e foi onde a "elite" da sociedade residiu por muitos anos.

Santos (2013) utiliza o termo tecido terciário para abarcar os espaços comerciais e de serviços das cidades e mostra que esse se revela por duas dimensões: quantitativa,
"[...] envolve o volume dos estabelecimentos, segmentado pelos diversos setores das atividades"; e qualitativa, "[...] engloba as características e as escalas do capital envolvido, bem como o grau de especialização da atividade" (SANTOS, 2013, p. 202). Para o autor, o tecido terciário é um elemento que faz parte do tecido urbano.

Nos chamados centros comerciais estão incluídos, em muitos casos, o bairro Centro e os que estão ao seu redor. Por isso, para Vilaça (1998), o centro é visto como uma conjuntura complexa que se interaciona com partes históricas e comerciais, onde os recursos estão com acesso

Os centros não são centros por que neles se localizam os palácios, as catedrais ou os bancos. Vimos que o oposto também é verdadeiro. Não é verdade que os palácios, catedrais ou bancos se localizam nos centros porque eles são centros. E por que eles são centros? Fica claro o círculo vicioso. Qual origem ou fonte da centralidade? Está na possibilidade de minimizarem o tempo gasto, os desgastes e os custos associados aos deslocamentos espaciais dos seres humanos. (VILLAÇA, 1998, p. 242)

Os processos de centralização tiveram origem no século XX e promoveram a concentração de serviços e atividades comerciais em cidades que conseguem ser responsáveis por gerir uma região mais ampla. Isso quer dizer que os centros são de extrema relevância nos serviços privados e públicos, bem com sistematizam formas de organização da estrutura administrativa. No caso estudado, o Centro Comercial de Feira de Santana apresenta esses mesmos aspectos, como se refere Corrêa:

A partir do começo do século $X X$ o processo de centralização e a sua correspondente forma espacial, a Área Central passaram a ser sistematicamente considerados pelos estudiosos do fenómeno urbano. [] De fato, a Área Central constitui-se no foco principal não apenas da cidade, mas de sua hinterlândia. Nela concentram-se as principais atividades comerciais, de serviços, da gestão pública e privada, e os terminais de transportes inter-regionais e intra-urbanos. (CORRÊA, 1995, p. 37)

As atividades comerciais e de serviços promovem integração de fluxos e deslocamentos no espaço intraurbano e fixam-se de modo que a concentração fortalece a centralidade urbana. Assim, Sposito (2001) traz a reflexão sobre centro e centralidade como a interligação entre ambos, já que o centro se mostra como a materialidade, dentro do espaço urbano, especificamente da área terciária, enquanto a centralidade, por sua vez, é concebida pela gama de elementos que, de modo dinâmico e na área central, entrelaçam o movimento de atividades que se completam e interagem simultaneamente. Sendo assim:

Se o centro se revela pelo que se localiza no território, a centralidade é desvelada pelo que se movimenta no território, relacionando a compreensão das centralidades, do plano conceitual prevalentemente 
à dimensão temporal da realidade. O que é central é redefinido em escalas temporais de médio e longo prazo pela mudança na localização de atividades. A centralidade é redefinida continuamente, inclusive em escalas temporais de curto prazo, pelos fluxos que se desenham através da circulação das pessoas, das mercadorias, das informações, das idéias e valores. (SPOSITO, 2001, p. 238)

Nas fases iniciais do capitalismo, o poder do capital industrial influenciava diretamente nos processos de gestões e organizações dos espaços das cidades, sobremodo com a invenção do automóvel, em 1885, por Gottlieb Daimler e Karl Benz, que três anos depois começaram a produção em escala (GIUCCI, 2004). E logo esse produto conquistou o gosto da sociedade alemã, por representar grande novidade tecnológica para época:

O automóvel é o símbolo por excelência do moderno no início do século XX. Sua chegada a diferentes partes do mundo ilustra a trajetória irresistivel da mobilidade. Chega à máquina bufante, o novo sáurio mecânico, o carro de fogo, envolvido numa nuvem de pó. E montado no cavalo mecânico chega o mensageiro da motorização. Enquanto o arauto medieval levava mensagens, determinava as festas de cavalaria e organizava os registros da nobreza, o piloto introduz o não visto e o estranho, na forma de antecipação do futuro. Vem de longe anunciando grande transformação. (GIUCCI, 2004, p. 263).

E mais, o automóvel promoveu um fator novo na mobilidade das cidades, pois encurtou o tempo das viagens pessoais e familiares, além de ter se tornado ferramenta de trabalho, claro que dentro das especificidades de cada classe social (SILVA, 2003). Ademais, as cidades também passaram por transformações e seus modos de organizações tiveram que ser revistos. O que antes eram ruas onde trafegavam carroças e cavalos, passaram a ser cenários onde as "maravilhas motorizadas" ganhavam espaços e adeptos paulatinamente, que ao mesmo tempo desejavam e admiravam, o que tempos depois seria considerada " $A$ máquina que mudou o mundo", por Womack (1992).

\section{ORIGEM DO SETOR DE AUTOPEÇAS NO BRASIL}

Os automóveis, que trazem em si um discurso de modernidade, se tornaram um objeto de desejo para o consumo, isso desde do século $X X$, quando passaram a ser um fator de status para alta sociedade. $O$ primeiro contato no Brasil aconteceu em:

São Paulo em 1893, o primeiro automóvel a rodar no País foi uma Peugeot, comprado em Paris. A máquina fez um giro pela Rua Direita, no então refinado Centro de São Paulo, o orgulhoso chauffer era o engenheiro brasileiro Henrique Dumont, milionário produtor de café na região de Ribeirão Preto, SP. (ANFAVEA, 2006, p.95)
Esse evento, até então inédito, logo se tornou algo normal para parte da sociedade paulista, mais favorecida financeiramente, que começou a ter contato com essas "máquinas sedutoras". Isso foi tão avassalador que o avanço do automóvel provocou impactantes mudanças sociais e no planejamento urbano e administrativo, já que até então o transporte era feito por cavalos, charretes e bondes com tração animal, que dominavam as ruas das grandes cidades. Em 1903, a grande metrópole paulista, como é conhecida hoje, possuía apenas seis automóveis. Em apenas um ano, a frota passou para 83 automóveis a circular pelas suas ruas, isso quer dizer que foi o primeiro "inchaço" automotivo na capital paulista. (ANFAVEA, 2006).

Com abertura do mercado brasileiro, as montadoras de automóveis viram novas perspectivas de investimentos. Assim nasceu a primeira montadora no Brasil, que importava peças e armavam os veículos para revenda. Em 1910, começava de modo ainda precário a consolidação do mercado de reposição de peças no país, pois foi "[...] quando surgiram os primeiros agentes importadores de veículos. Era o embrião da rede brasileira de distribuição de veículos. As primeiras concessionárias autorizadas datam de 1920, época em que começou a montagem de veículos CKD no Brasil" (ANFAVEA, 2006.p 80).

Segundo a ANFAVEA (2006), a primeira montadora oficial no Brasil foi a Ford que, em 1919, começou a importar os primeiros kits CKD, para montagem do seu modelo mais famoso e produzido na sua história que é o Ford T.

Logo após, seguindo a tendência de busca por novos mercados, a General Motors chegou ao Brasil e à Argentina, por meio da Manufacturing Facility, que foi registrada no Tabelionato de São Paulo, no dia 26 de janeiro de 1925 . Foi quando deu início a construção da primeira linha de montagem. O local escolhido era um grande galpão no bairro Ipiranga, símbolo da emergência industrial da metrópole nos anos de 1920, próximo da ferrovia Santos-Jundiaí. A companhia trazia em CKDs, veículos totalmente desmontados, todos os seus modelos das marcas Buick, Oldsmobile, Chevrolet, Oakland, Cadillac e Pontiac. Em outubro de 1929, a fábrica já podia funcionar. A GM foi a primeira montadora a inaugurar uma fábrica no pais, localizada no município de São Caetano do Sul(A COMPANHIA..., 2015.).

Nos anos seguintes, também veio ao Brasil a International Harvester para começar a montagem de caminhões, pioneira no seguimento. Logo depois, se instalou a fábrica Italiana de Automobili Torino, conhecida como FIAT. Em 1939, foi a vez do Brasil iniciar, ainda de forma prematura, seu primeiro passo tecnológico com a criação da estatal chamada Fábrica Nacional de Motores, conhecida na atualidade pela sigla FNM, que, no seu início, foi fabricante de motores aeronáuticos para Força Aérea Brasileira (FAB). (ANFAVEA, 2006).

Uma década depois, começaram a surgir as primeiras fábricas de caráter privado nacional, que produziam equi- 
pamentos de combustíveis alternativos, pois, no período, existia a crise de petróleo em escala mundial, no contexto das guerras. Uma das empresas foi a Metalúrgica João Wiest, fundada 1947, em Jaraguá do Sul, em Santa Catariana. Essa empresa construía e instalava aparelhos de gasogênio e, a grosso modo, essas máquinas tinham funções de queimar lenha e carvão em um alojamento externo dos veículos e conduzir gases por meio de tubulações que eram injetados no carburador. (APRESENTAÇÃO..., 2017).

Na década de 1950, começou a se consolidar o setor de autopeças no Brasil com a criação do Sindicato Nacional da Indústria de Componentes para Veículos Automotores (Sindipeças), com apenas caráter estadual, o qual, em 1953, realizou a Primeira Mostra da Indústria Nacional de Autopeças, inaugurada em 20 de janeiro de 1953, pelo presidente Getúlio Vargas, no saguão do Aeroporto Santos Dumont, no Rio de Janeiro. (ANFAVEA, 2006).

O Sindipeças só passou a ser uma entidade de caráter nacional em 1976, e hoje possui sua sede em São Paulo e representações nos estados de Minas Gerais, Paraná, Rio de Janeiro, Rio Grande do Sul e Santa Catarina, além de um escritório executivo em Brasília. Essa Instituição tem o papel de auxiliar e organizar uma parte do setor automotivo de autopeças (INSTITUCIONAL, 2017b).

O mercado de autopeças pode ser definido como um setor de prestação de serviços para o mercado de reposição do automobilístico, em que se disponibiliza uma variedade de produtos e marcas, com o intuito de suprir a deficiência de mercado deixada pelas concessionárias oficializadas, assim como preencher essa lacuna de mercado e promover a livre concorrência.

$\mathrm{Na}$ verdade, a autopeças trata-se de um complexo sistema de ligação entre indústria, distribuição e o serviço final, que é feito de fato pelas lojas. Essas podem ser de balcão, as denominadas autocenter, ou mistas, que são vendas de instalação de peças, as quais constituem os centros automotivos. As lojas são agentes de relacionamento direto com as oficinas mecânicas e com o consumidor final, pois, em seu cotidiano, além de ser um prestador de serviços e do comércio de produtos, têm papel, quase sempre esquecido, de fazer a integração social, pois diferentes classes de profissionais interagem.

Ainda assim, o setor de autopeças segue uma hierarquia na cadeia produtiva, em se apresenta como o elo mais vulnerável na rede, como afirma Bedê, em relação à política automotiva dos anos de 1990:

Além disso, frente ao setor montador, o seguimento de autopeças apresenta um maior número de imperfeiçoes de mercado. Predominado ali empresas com menor capacitação tecnológica, com menor habilidade para acessar as informações disponíveis, dificuldade de trabalhar com uma perspectiva de logo prazo e que tem de fazer frente a uma relação de fornecimento do tipo oligopólio-monopólio, junto as montadoras. (BEDÊ, 1997, p 385)
Esse tipo de monopólio é praticado pelas montadoras que protegem seus agentes revendedores, já que os recursos tecnológicos ficam com o domínio desses agentes, ou melhor, das concessionárias. Essas apesentam diversificações e variações nos serviços prestados aos consumidores.

Além disso, a concorrência entre os agentes autorizados e o mercado paralelo de autopeças é discrepante, pois vai desde a infraestrutura, o modelo de organização e gestão, até a capacitação dos profissionais do setor. No setor de autopeças há contrastes de organização estrutural claros, já que cada estabelecimento possui uma particularidade e esse modo organizacional, normalmente, é moldado pelos proprietários.

O mercado segue uma tendência, já que, na maior parte, as autopeças apenas são responsáveis pela revenda de peças e acessórios para veículos, devido a alguns fatores: os altos custos de maquinário para manutenção veicular, a diversidade da frota atual, a falta de profissionais qualificados e de instalações amplas, sem contar que todos elementos ferramentais precisam ser instalados por profissionais enviados pelos fabricantes, os quais são também responsáveis pela manutenção. Tudo isso, algumas vezes, inviabiliza a instalação de uma empresa de porte misto, entre peças e serviços.

As relações de consumo são também bastante diversificadas, pois vão desde o ato de aquisição dos produtos pelos lojistas até o resultado final, que é a concretização da venda. Esse processo passa por uma série de etapas, que enlaça a cotação de preços e envolve fornecedores os mais diversos da cadeia produtiva. Como os grandes polos industriais e centros distribuidores estão na Região Sudeste do Brasil, cerca de $70 \%$ dos produtos comercializados pelo mercado de autopeças vêm desse estado. Outros $20 \%$ são adquiridos dentro do próprio Estado da Bahia e os outros 10\% são de fornecedores dos estados do Rio de Janeiro, Santa Catariana, Goiás, Paraná e Rio Grande do Sul ${ }^{1}$.

\section{ORIGEM DO SETOR DE AUTOPEÇAS NA CIDADE FEIRA DE SANTANA.}

No caso de Feira de Santana, a delimitação do bairro Centro é relativamente diferente em relação ao que se concebe como centro comercial, ou melhor, centro terciário. $\mathrm{O}$ bairro Centro fica situado dentro Anel de Contorno, onde se localiza, nos dias atuais, talvez a maior parte dos estabelecimentos relacionados ao comércio e à prestação de serviços.

A delimitação definida pela Prefeitura Municipal de Feira de Santanaordena que o bairro Centro, no âmbito oficial, faz contato com o Chácara São Cosme, Brasília, Baraúnas, Tanque da Nação, Pedra do Descanso, Caseb, Queimadinha (FEIRA DE SANTANA, 2004). Esses bairros são na verdade extensões do centro comercial, já que vários estabelecimentos terciários também estão neles inseridos.

Assim, o centro comercial apresenta um tecido terciário que é mais amplo, pois, ainda que os bairros circunvizinhos mostrem características vistas no bairro Centro, por outro 
lado, o tecido terciário é estruturado em uma área bem maior que a delimitação política do bairro. Como há circulação e movimentação de pessoas e fluxo de trânsito, também é constante nessas áreas que rodeiam o bairro Centro a proliferação de atividades terciarias diversificadas, as quais permitem entender que o termo centro comercial, neste texto, ultrapassa o Centro definido oficialmente, que apresenta objetivos administrativos mais limitados.

O setor de autopeças, como parte específica do comércio e dos serviços, teve início mais claro das suas atividades em Feira de Santana na década de 1960, com a implantação da primeira concessionária na cidade, que se chamava Juca Dias Comércio de Veículos, que representava a multinacional americana Willys Overland. Essa comercializava e também prestava serviços de manutenção aos modelos vendidos para a cidade e a região. A sede da empresa ficava situada às margens da Avenida Presidente Dutra².

Ainda nessa década, a Auto Queiroz, inaugurada em 1965 por Belamino Queiroz e Guilhermino Queiroz, ficava localizada no Centro da cidade, na Praça Padre Ovídio, e só comercializava peças para automóveis das linhas leves e médias, isso quer dizer carros de passeio e Pick up. Em 1967, a empresa abriu uma filial na Avenida Senhor dos Passos, vizinha ao antigo Cine Iris, esse que era um ponto de encontro da burguesia feirense na época ${ }^{3}$.

A Auto Martins foi a terceira empresa a se instalar em Feira de Santana, sendo fundada por Candido Martins de Queiroz, situada também na praça Padre Ovídio. O proprietário era o pai dos donos da Auto Queiroz, o que mostra certa relação familiar no ramo. Também vendia peças de reposição de veículos, mas com uma ressalva, pois já trabalhava com o seguimento de veículos da linha pesada, tais como caminhões e ônibus. $\mathrm{O}$ estabelecimento manteve suas atividades até o falecimento do seu proprietário e, após isso, seu estoque foi incorporado a Auto Queiroz ${ }^{4}$.

A Casa das Peças estava instalada na Avenida Presidente Dutra e ficava na esquina com a Rua Barão do Rio Branco, no bairro Centro, e comercializava peças e acessórios. Também na mesma avenida abriu a Tio Sam autopeças, de propriedade de Luiz Queiroz, filho do senhor Guilhermino Queiroz, da Auto Queiroz, isso em $1969^{5}$. Outra foi a Autopeças Pereira, que se localizava na Avenida Senhor dos Passos, na esquina com a Rua Santos Dumont, no Centro. Nessa época, a loja ficava próximo ao posto de abastecimento de querosene ${ }^{6}$, que hoje é a Praça do Nordestino?

A Gerson Rocha foi a primeira concessionária da General Motors a ser implantada na cidade de Feira de Santana e ficava situada na Praça Dr. Jackson do Amauri. Essa loja manteve suas atividades entre os anos de 1968 até 1974, quando fechou as portas ${ }^{8}$.

A Potiguar Autopeça começou suas atividades no setor em 1969, sendo fundada pelo senhor Abner Cosme Deiro, com sua primeira loja situada na rua Washington Luiz, no bairro Queimadinha. Em 1972, o estabelecimento mudou a sede para Avenida Presidente Dutra. Ainda no mesmo ano, abriu sua primeira e única filial na cidade de Salvador, na rua Padre Antônio de Sá, bairro dos Mares ${ }^{9}$.

Nota-se que, na década de 1960, esses estabelecimentos comerciais se localizavam basicamente às margens das rodovias que cortavam o Centro da cidade de Feira de Santana, mais especificamente na atual Avenida Presidente Dutra, que faz a ligação entre as BR 324 e BR 116, entre os eixos norte-sul. No eixo norte, começavam a se instalar em as primeiras empresas de autopeças, na Rua Visconde do Rio Branco.

Na década de 1970, com a expansão do número de modelos e de marcas de automóveis que estavam sendo comercializados no país, como decorrência isso influenciou a atividade na Bahia e em Feira de Santana. Também houve relativa evolução financeira da sociedade feirense e da região, período da implantação do Centro Industrial Subaé (CIS), discutida por Freitas (2009), o que se tornou atrativo para criação de novas concessionárias das principais montadoras existentes no Brasil, na época.

Assim, em 1972, foi fundada a Norauto veículos, pelo Sr. Modesto Cerqueira, criador do Grupo Modesto Cerqueira (MC), com atitude pioneira e incentivado por seu filho, Modezil Cerqueira. A iniciativa proporcionou ao Grupo MC vasta experiência no setor automotivo, que representava a Ford Motor Company, tanto na linha leve, que são os automóveis, quanto na linha pesada, que é composta por caminhões. Por quanto, hoje, é um dos maiores empresários da sua atividade nas regiões Norte e Nordeste do país (O GRUPO..., 2017)

Fundada em 1975, a Paraguassu Veículos tem em todas as suas sedes a missão de levar tecnologia de ponta, atendimento de alto nível e os mais elevados padrões de aperfeiçoamentos técnicos, unidos à qualidade única da General Motors do Brasil, que também atua em Alagoinhas, Serrinha, Cruz das Almas e Santo Antônio de Jesus, isso relacionado ao Estado da Bahia. (INSTITUCIONAL..., 2017a)

A Feira Motor Concessionária Volkswagen foi fundada em meados da década de 1970 e se localizava na Avenida Presidente Dutra, a qual funcionou até 2006. A Comercial de Automóveis foi outra concessionaria da Volkswagen na cidade de Feira de Santana, que também foi fundada em meados dessa mesma década e funcionou até 2003, quando foi vendida e incorporada ao Grupo Bremem veículos. (FEIRA DE SANTANA..., 2017)

Nos anos de 1980, foi a vez da Fiat Automóveis do Brasil ter sua primeira representação na cidade de Feira de Santana, com a chegada da Jacuípe Veículos, que é, talvez, a maior Concessionária da empresa no Interior da Bahia. Foi fundada em 1983, também pelo Grupo MC. (FIAT 147..., 2017)

A partir da década de 1970, começaram a surgir com mais veemência as chamadas autopeças independentes, não ligadas às montadoras. Com isso, começaram a se formar setores com áreas mais específicas para cada segmento, 
esses que se subdividiram em partes de acessórios e partes mecânicas. As empresas mais especializadas em acessórios automotivos, em sua maioria, se implantaram no eixo da Rua Marechal Floriano Peixoto, popularmente conhecido como Largo do Shell ou Marajó, e também para rua Visconde do Rio Branco, na junção com a Avenida José falcão da Silva ${ }^{10}$.

As empresas que se aprimoraram em peças mecânicas e elétricas seguiram, em prevalência, com a formação de outros eixos e se concentraram mais na Praça da República, Rua Carlos Valadares, Rua São José rua Visconde do Rio Branco e Avenida Presidente Dutra. Essa estrutura de localização ainda é a bem mais visível, mesmos que, posteriormente, tenha havido a expansão para outras áreas, localizadas mais próximas do perímetro urbano de Feira de Santana, que foi o eixo do Anel Viário.

Por sinal, o eixo do Anel Viário também tem papel importante na localização de estabelecimentos nesse setor, sobretudo, devido à falta de espaço amplos para instalações das concessionárias e das grandes redes de distribuição, algumas das quais migraram para essa parte da cidade. Isso ocorreu, sobremodo, a partir da década de 1990, principalmente por exigências das montadoras, que começavam a investir em novas tecnologias no setor automotivo brasileiro, isso na chamada "Era Collor", quando houve grande transformação no setor automobilístico nacional.

Outro fator impactante no setor de autopeças brasileiro foi a transformação da economia, em 1994. Com a implantação do Plano Real, muitas empresas não se adequaram e encerraram suas atividades em várias cidades do país, que durante anos viveu certa falácia, o argumento de que nesse setor há falta de profissionais para atuar na área.

Dentre as mudanças ocorridas no setor de autopeças na cidade de Feira de Santana, talvez a mais notada aconteceu a partir de 1999, isso nas áreas recortadas para este texto. A área que fica localizada na Praça da República e na Praça Presidente Médici, onde existia o comércio e prestação de serviços de autopeças, com várias lojas e oficinas mecânicas, foi praticamente extinta, sobremodo, devido ao deslocamento do comércio de produtos e de serviços importados, que antes estavam situados no calçadão da Rua Sales Barbos. Esse processo de transferência foi organizado pela Prefeitura Municipal de Feira de Santana, em 1996, e com isso aquele espaço passou por grande modificação, porque onde era antes uma área de menor valor comercial, passou por alta valorização e assim o setor de autopeças e serviços, representado pelas oficinas mecânicas, foi, aos poucos, desaparecendo no local ${ }^{11}$.

Essas mudanças causaram mais impactos a partir de 2002, na Praça da República, sobretudo face o aumento dos preços dos aluguéis de imóveis. Com isso, uma parte desse setor foi deslocada para outras áreas do centro comercial. Nota-se que, nessa área, onde ficavam localizadas 17 lojas de autopeças, em 2015, hoje restaram apenas 5. Das 17 verificadas, 4 delas migraram para a avenida Presidente
Dutra, entre os bairros Centro e Capuchinhos. As outras foram extintas e alguns proprietários dessas lojas, em que os imóveis eram próprios, optaram por alugar seus estabelecimentos ou mesmo fecharem as lojas ${ }^{12}$.

Com o enfraquecimento do comércio e da prestação de serviços de autopeças nessa parte do centro comercial de Feira de Santana, uma outra área ganhou maior valorização e essa é onde hoje se localiza a maior parte das autopeças, que é a "região" conhecida como "Saída de Serrinha", que fica às margens da avenida Jose Falcão da Silva. No sentido inverso, seguiram as concessionárias, que, devido as exigências das montadoras, foram forçadas a buscar espaços mais amplos e optaram por instalar suas empresas às margens do Anel Viário e da BR 324, isso se levarmos em consideração apenas as montadoras de veículos de linha leve ${ }^{13}$.

No que diz respeito ao comércio de peças e a prestação de serviços para veículos da linha pesada, as lojas estão mais distribuídas pelas margens do Anel Viário, da BR 116, sentidos sul e norte, da BR 324 e da BR 101, óbvio que isso ocorre devido ao maior fluxo desse tipo de veículo.

\section{CONSIDERAÇÕES FINAIS}

Em uma cidade comercial onde seu foco econômico maior é o setor terciário, isso funciona como uma "locomotiva" que impulsiona toda região. Assim é Feira de Santana, considerada um polo dinamizador, não só de sua região, mas sim de todo o estado da Bahia. No fator de prestação de serviços e no comércio, recorte deste artigo, destaca-se o setor automotivo,tão importante no dia a dia da população, além de movimentar uma economia própria, em sua cadeia de produção, que segue desde os insumos em formato bruto, até alcançar o fim do processo de industrialização para chegar ao mercado.

A trajetória do setor de autopeças em Feira de Santana é importante para a dinâmica da cidade, pois, como é considerada entreposto comercial e locus da locomoção de milhares de pessoas, o setor de autopeças tem uma página nessa trajetória histórica, bem como na época contemporânea. É um segmento para prestação de serviços e abasteceos mercados interno e externo, isso na reposição de peças para veículos.

\section{NOTAS}

${ }^{1}$ Informações coletadas em 2017, com base em dados do relacio-namento de compras de uma empresa de Autopeças de Feira de Santana.

${ }^{2}$ ANTONIO DE JESUS. Entrevista realizada em março de 2017

${ }^{3}$ ARABUTAN DE QUEIROZ. Entrevista realizada em março de 2017 ${ }^{4}$ Idem

${ }^{5}$ Idem

${ }^{6}$ Posto de querosene, pois, na época, não havia abastecimento de energia elétrica fora do Centro da cidade, já que a cidade passou por expansões até chegar a configuração atual. 
${ }^{7}$ ANTONIO DE JESUS. Entrevista realizada em março de 2017

8Idem

Idem

${ }^{10}$ Informações coletadas em 2017, com base em dados da pesquisa realizada por Pereira (2018)

${ }^{11}$ Idem

${ }^{12}$ Idem

${ }^{13}$ Idem

\section{REFERÊNCIAS}

A COMPANHIA. Disponível em: <http://www.chevrolet.com. br/sobre-gm/a-companhia.html>. Acesso: 27 mai. 2017.

ANFAVEA. Indústria Automobilística Brasileira 50 anos. Editora Autodata. São Paulo. 2006.

APRESENTAÇÃO. Wiest. Disponível em: <http://www.wiest. com.br/>. Acesso: 27 mai. 2017

BEDÊ, M. A. A política automotiva nos anos 90, in ARBIX, G., ZILBOVICIUS, M. (Org.). De JK a FHC: a reinvenção dos carros. Editora Scritta, São Paulo, 1997,p. 357-388.

BENÉVOLO, Leonardo. História da cidade. São Paulo: Perspectiva, 1997.

CORRÊA, Roberto Lobato. O espaço urbano. 3a. ed. São Paulo: Editora Ática, 1995.

FEIRA DE SANTANA. Lei Complementar $n \circ \mathbf{1 8 ,} 08$ de julho de 2004. Define o perímetro urbano, delimita os bairros da cidade de Feira de Santana e dá outras providências. Feira de Santana. 08 jul. 2004. Disponível em: <http://www. feiradesantana.ba.gov.br/leis.asp?acao=baixa\&arquivo=leic omp18.pdf>. Acesso em 15 junho. 2017.

FEIRA DE SANTANA. Bremen. Disponível em: <https://www. bremenvolks.com.br/feira-de-santana>. Acesso: 27 mai. 2017.

FIAT 147: comercial antigo de lançamento 1976 - Brasil. Jacuípe Veículos. Disponível em: <http://jacuipeveiculos. blogspot.com.br/>. Acesso: 27 mai. 2017.
FREITAS, N. B. Modernização Industrial em Feira de Santana: Uma análise da implantação do Centro Industrial do Subaé CIS. Sitientibus, n. 41, 2009, p. 139-160

GIUCCI, G. A vida cultural do automóvel: percursos da modernidade cinética. Rio de Janeiro: Civilização Brasileira, 2004

INSTITUCIONAL. Paraguaçu Veículos. Disponível em: <https://www.paraguassuveiculos.com.br/institucional-naconcessionaria-e-revenda-autorizada-chevrolet-em-feirade-santana-alagoinhas-santo-antono-de-jesus-e-serrinhaba-paraguassu>. Acesso: 27 mai. 2017a.

INSTITUCIONAL. SINDIPEÇAS. Disponível em: <www.sindipeças. org.br>. Acesso: 27 mai. 2017b.

O GRUPO MC. Norauto Veículos. Disponível em: <https:// norautoveiculos.com.br/conheca-nos>. Acesso: 27 mai. 2017.

PEREIRA, Anselmo Pereira de. (Des)organização espacial do setor de autopeças em Feira de Santana: o Centro Comercial entre os anos de 1996/2016 em análise, 2018. 110f. Monografia (Bacharelado em Geografia) - Universidade Estadual de Feira de Santana, 2018.

SANTOS, J. A cidade poli(multi)nucleada: a reestruturação do espaço urbano em Salvador.Salvador, EDUFBA, 2013.

SANTOS, Milton. A natureza do espaço: técnica e tempo, razão e emoção. São Paulo: HUCITEC, 1996.

SILVA, R. Indústria automobilística brasileira nos anos 90: uma nova territorialização. Boletim Goiano de Geografia, Revista de Geografia da Universidade Federal de Goiás (UFG), v. 23 , n. 1,2003 , p. 58-81.

SPOSITO, M. E B. Novas formas comerciais e a redefinição da centralidade intra-urbana. In: SPOSITO, M. E B. (Org). Textos e Contextos para a leitura geográfica de uma cidade média. Presidente Prudente: [ s.n.]. 2001.

VILLAÇA, Flávio. Espaço intra-urbano no Brasil. São Paulo: Studio Nobel, 2001.

WOMACK, James P. A máquina que mudou o mundo. Rio de Janeiro: Campus, 1992. 